\title{
Treating Depressed Children With Antidepressants: More Harm than Benefit?
}

\author{
David Antonuccio
}

Published online: 18 July 2008

(C) Springer Science+Business Media, LLC 2008

Erratum to: J Clin Psychol Med Settings (2008) 15:92-97

DOI 10.1007/s10880-008-9108-9

In Table 1 on page 4 of this article, the third, fifth, seventh and ninth column sub-heads indicate 18 mos FU. They should read 9 mos FU.

The online version of the original article can be found under doi: 10.1007/s10880-008-9108-9.

D. Antonuccio $(\bowtie)$

Department of Psychiatry and Behavioral Sciences,

University of Nevada School of Medicine, Reno, NV, USA

e-mail: Oliver2@aol.com 